\title{
Parenthood and factors that influence outdoor recreational physical activity from a gender perspective
}

\author{
Katarina Sjögren ${ }^{1,2^{*}}$, Eva Ekvall Hansson $^{1 \dagger}$, Louise Stjernberg ${ }^{2 \dagger}$
}

\begin{abstract}
Background: A physically active life promotes both physical and mental health, increasing well-being and quality of life. Physical activity (PA) performed outdoors has been found to be particularly good for promoting well-being. However, participation in PA can change during the course of a lifetime. Parenthood has been found to be a life event associated with decreased PA, especially among women, although studies in the field are sparse. The aim of this study was to investigate participation in outdoor recreational PA, and factors influencing participation among parents-to-be, with and without previous children, from a gender perspective.

Methods: This study included baseline data from parents-to-be, 224 women and 208 men, from the municipality of Karlskrona in south-east Sweden. Data collection was carried out during 2008-2009. We measured the selfreported amount of outdoor recreational PA undertaken during the last year and analysed the probability of participating in this PA using 25 variables covering individual and socioeconomic factors.

Results: Seventy-six per cent of the women and $65 \%$ of the men had participated in outdoor recreational PA, varying from several times per month to every day, over a 12-month period prior to one month before pregnancy. Participation in PA indoors and owning a dog or a horse emerged as the most important factors associated with the probability of participation in outdoor recreational PA. Men were affected by a greater number of factors than women, for example men who had a family situation that permitted outdoor recreational PA participated in activities to a greater extent than men without such a family situation. The physical aspect, i.e. improved physical condition, staying power and vigour, also played a significant role with regard to participation among men.

Conclusions: Becoming a parent is a life-changing event that affects participation in PA. By offering familyoriented PA choices that involve both parents and children, midwives and health promoters can encourage parents to be active and to support each other. The promotion of outdoor recreational PA, which also has restorative effects on well-being, needs to focus on activities which are attractive and affordable for the majority of both women and men.
\end{abstract}

\section{Background}

Being physically active promotes both physical and mental health, increasing well-being and quality of life $[1,2]$. Physical activity (PA), defined as "any bodily movement produced by the contraction of skeletal muscle that increases energy expenditure above a basal level" [3], is

\footnotetext{
* Correspondence: katarina.sjogren@med.lu.se

† Contributed equally

${ }^{1}$ Faculty of Medicine, Department of Clinical Sciences in Malmö, General Practice, Lund University, CRC entrance 72:28:11, Malmö University Hospital, 20502 Malmö, Sweden

Full list of author information is available at the end of the article
}

associated with a wide range of health benefits, including mitigation of chronic health problems as well as improvements in mental health and well-being [2]. Participation in PA outdoors promotes well-being and evidence has been found for a positive relationship between green space and self-perceived health [4-6]. It has also been found to have restorative effects on human health and a reduction in mental fatigue $[7,8]$. Outdoor recreational PA is defined here as being outside in natural or cultural landscapes for the purpose of well-being and encounters with nature without any demand for competition [9].

\section{Biomed Central}


Despite the well-documented health benefits of PA, inactivity was identified in 2009 as the fourth leading cause of chronic diseases and mortality globally and contributes to more than three million preventable deaths worldwide [10]. According to Sjöström et al [11] only $23 \%$ of the Swedish adult population are sufficiently active for optimal health benefits. The situation is similar in other western European countries and the United States. In general, women tend to be less physically active than men $[1,11,12]$.

Participation in PA can change over a lifetime and from a public health perspective it is important to understand how life events may impact on participation in PA. Periods of life transition may be associated with changes in health-related behaviour such as PA [13]. Parenthood is a life event associated with decreased PA, especially among women $[14,15]$. A review of PA and parenthood by Bellows-Riecken and Rhodes [15] shows a negative relationship between parenthood and participation in PA in 14 of the 17 studies examined. Brown et al [16] found women with children performed less PA than women without children and Schmitz et al [17] found that parenthood resulted in reduced PA in women but not in men, with the biggest difference occurring during first parenthood. Lack of time and social support, fatigue, childcare, and other obligations have been identified as factors that impacted negatively on parents' participation in PA [18-21].

As parents play an important role in the socialisation and development of PA patterns in their children, knowledge of determinants that affect participation in PA among both parents as well as parents-to-be is necessary to develop effective health-promotion programmes. Studies in the field are sparse, and there is a particular lack of data about differences in PA patterns between men with and without children, as well as between women and men with children [15]. The aim of this study therefore was to investigate participation in outdoor recreational PA, and factors influencing participation among parents-to-be, with and without previous children, from a gender perspective.

\section{Methods}

\section{Study area, participants, and design}

This study includes baseline data from parents-to-be with and without previous children. Those who already had children are in this study named either "parents" or "women/men with children" and those who did not have previous children and were now expecting their first child are either named "non-parents" or "women/ men without children". The data were collected between March 2008 and February 2009 from the municipality of Karlskrona. Karlskrona, an urban region with 62,900 inhabitants, is located in south-east Sweden on the
Baltic Sea and both woodland and archipelago settings are readily accessible.

On finding themselves pregnant, Swedish women book an initial meeting with a midwife through an antenatal clinic, in most cases at 8-10 weeks of pregnancy. Parents-to-be who contacted either of the two antenatal clinics in Karlskrona were invited by the midwife to participate in this study. If they agreed to participate in the study, separate questionnaires (with different colours) were sent by post to the woman and her partner, and were returned to the midwife at the initial meeting.

The majority of the questions had been applied and validated in the Swedish Survey of Living Conditions (ULF) and in a national survey about outdoor life and nature tourism in Sweden [9]. Some extra added questions were tested in a pilot study $(\mathrm{n}=10)$ and there was no need for adjustment before use. Identical questions were used for both women and men, and the respondents were required to address their situation one month before pregnancy. The questionnaires, which were filled in retrospectively, investigated age, cohabitation, level of education, personal financial situation, living conditions, dog or horse ownership, tobacco and alcohol consumption, and previous children and their age. Questions about outdoor recreational PA concerned activities during the previous 12 months (calculated from one month before pregnancy) and reasons for participation (i.e. to benefit for physical and/or social reasons and/or the adventure and/or restorative effects and also to attain well-being).

The questionnaires also included questions about obstacles to participating in outdoor recreational PA (abandoning outdoor activities during the evenings due to fear of violence, cost, the experience of activities being too demanding physically, limitations due to the family situation, illness/functional disorder) and other considerations (lack of appropriate areas to perform it in, equipment, time, courage, interest, or too little knowledge about how to perform activities). The participants also answered questions about indoor PA during the previous 12 months. The inclusion criteria were pregnant woman who spoke Swedish. The exclusion criteria were woman who had experienced miscarriage or other complications during previous pregnancies or deliveries or if the midwife did not consider it suitable to ask about participation in the study due to the woman's general state of health.

Outdoor recreational PA was measured by the survey question "How often have you participated in outdoor recreational PA during the last 12 months?" Participants were asked to mark activities participated in during the last 12 months from a list of 24 outdoor recreational activities from a Swedish national survey dealing with 
outdoor recreational life [9]. This list included a wide spectrum of physical and more sedentary activities, as we wished to include activities with a restorative effect on well-being as well as activities associated with physical effort. The following activities were presented: strolling in the woods and fields, walking, jogging, orienteering, Nordic walking, golf, biking, rollerblading, bathing, diving, canoeing, sailing, angling, motorboating, skating, cross-country skiing, downhill skiing, tobogganing, sunbathing, hunting, cross-country riding, bird-watching, camping in the countryside and gardening.

\section{Statistical analysis}

In the statistical analyses a chi-squared test was used to compare proportions between groups. When the expected frequencies were $<5$ in any group, Fisher's exact test for the comparison of two proportions was used. Multivariate analyses were carried out by means of logistical regression models (method: backward conditional), with participation in outdoor recreational PA as the dependent variable. Participation in outdoor recreational PA was dichotomised into "active" (if a person participated in activities several times ( $>3$ times per month) a month to every day) and "not active" (if a person never participated in activities or up to 2-3 times per month).

Simultaneous relationships between the dependent variable and all independent variables were modelled and evaluated using odds ratios (ORs). Two different models were tested separately for 1 ) women with children, 2) women without children, 3) all women, 4) men with children, 5) men without children, and 6) all men. In the first model, all independent variables from the questionnaire were included. The second model included variables from the first model for which a significant impact on the probability of participation in outdoor recreational PA existed between the independent variables that included more than five participants in each combined group. The second model also evaluated the interactions between these variables, with a $\mathrm{p}$-value $<0.005$. The statistical significance of the variables was determined using a $95 \%$ confidence interval (CI). Data were computerised and analysed using SPSS 17.0 for Windows. This study was approved by the Regional Ethical Review Board in Lund, Sweden.

\section{Results}

During the study period, 669 women were registered at the two local antenatal clinics. Of these, 431 met the inclusion criteria and upon inclusion the women ranged from week six to week 33 of pregnancy (mean 11 weeks). The mean age of non-participating women was 30 years. The reasons for non-participation were unwillingness, unsuitability for study inclusion (as determined by the midwife), and non-compliance with the inclusion criteria. A total of 224 women and 208 men agreed to participate. Of the women, 121 had children, and of those, 115/121 (95\%) had children aged 0-5 years. Of the men, 113 had children, and of those, 106/ 113 (94\%) had children aged 0-5 years. Of the women included, 171/224 (76\%) had participated in outdoor recreational PA several times per month to every day during the last 12 months up to one month before pregnancy, and 135/208 (65\%) men had participated in activities several times per month to every day during the same period. Outdoor recreational activities had a positive impact on feelings of well-being in 221/224 (99\%) women and 198/208 (95\%) men. More than half of the women and men had a higher education and the majority of them were able to cover an unexpected cost within a week (Table 1). The demographic characteristics of study participants are presented in Table 1.

All variables from the questionnaire are shown in Table 2, and Table 3 contains participation in different kinds of PA during the last 12 months. All those who participated in non-physical strenuous activities also participated in at least one physical activity. Women strolled and walked significantly more (Pearson chisquare $=5.724, p=0.017$ ) than men irrespective of whether or not they had children. In all other activities studied, no significant differences were seen between women and men. Women with children participated in significantly more winter sports (Pearson chi-square $=$ 6.213, $p=0.013$ ) and gardening (Pearson chi-square $=$ 9.417, $p=0.009$ ) than women without children, and women without children participated in significantly more PA indoors (Pearson chi-square $=14.877, p<$ $0.001)$ than women with children. Men with children participated in significantly more gardening (Pearson chi-square $=20.799, p<0.001)$ than men without children, and men without children participated in significantly more PA indoors (Pearson chi-square $=7.687$, $p=0.006)$.

\section{Differences between groups and factors significantly associated with participation in outdoor recreational PA among women}

Factors significantly associated with outdoor recreational PA among all women with and without children were ownership of a dog or horse (Fisher's exact test $p<$ 0.001), participating because of well-being (Fisher's exact test $p=0.022$ ), and participating in activities indoors (Pearson chi-square $=11.366, p=0.001)$. The only factor that significantly enhanced participation in outdoor recreational PA among women with children was ownership of a dog or horse (Fisher's exact test $p<0.001$ ). Among women with no children, a higher level of education (Pearson chi-square $=4.833, p=0.028$ ), $\operatorname{dog}$ or 
Table 1 Participant characteristics one month before pregnancy

\begin{tabular}{|c|c|c|c|c|c|c|}
\hline & $\begin{array}{l}\text { Men with } \\
\text { children }\end{array}$ & $\begin{array}{l}\text { Men without } \\
\text { children }\end{array}$ & $\begin{array}{l}\text { All } \\
\text { men }\end{array}$ & $\begin{array}{l}\text { Women with } \\
\text { children }\end{array}$ & $\begin{array}{l}\text { Women without } \\
\text { children }\end{array}$ & $\begin{array}{l}\text { All } \\
\text { women }\end{array}$ \\
\hline Variables (\%) & $\begin{array}{l}n=113 \\
(\%)\end{array}$ & $\begin{array}{l}n=95 \\
(\%)\end{array}$ & $\begin{array}{l}n= \\
208 \\
(\%)\end{array}$ & $\begin{array}{l}n=121 \\
(\%)\end{array}$ & $\begin{array}{l}n=103 \\
(\%)\end{array}$ & $\begin{array}{l}n=224 \\
(\%)\end{array}$ \\
\hline Mean age & 34 & 31 & 32 & 31 & 28 & 30 \\
\hline Cohabiting $^{1}$ & $102(99)$ & $94(99)$ & $206(99)$ & $119(98)$ & $102(99)$ & $221(99)$ \\
\hline Lower education ${ }^{2}$ & $49(43)$ & $40(42)$ & $89(43)$ & $55(45)$ & $42(41)$ & $97(43)$ \\
\hline Higher education ${ }^{3}$ & $64(57)$ & $55(58)$ & $119(57)$ & $66(55)$ & $61(59)$ & $127(57)$ \\
\hline $\begin{array}{l}\text { Personal financial } \\
\text { situation }^{4}\end{array}$ & $100(89)$ & $83(87)$ & $183(88)$ & $102(84)$ & $88(85)$ & $190(85)$ \\
\hline Living in the countryside ${ }^{5}$ & $49(43)$ & $24(25)$ & $73(35)$ & $52(43)$ & $27(26)$ & $79(35)$ \\
\hline Living in a town ${ }^{6}$ & $64(57)$ & $71(75)$ & $135(65)$ & $69(57)$ & $76(74)$ & $145(65)$ \\
\hline Owning a dog or a horse & $31(27)$ & $17(18)$ & $48(23)$ & $32(26)$ & $20(19)$ & $52(23)$ \\
\hline Being a smoker ${ }^{7}$ & $22(20)$ & $18(19)$ & $40(19)$ & $16(13)$ & $27(26)$ & $43(19)$ \\
\hline Using snuff ${ }^{8}$ & $43(38)$ & $34(36)$ & $77(37)$ & $2(2)$ & $3(3)$ & $5(2)$ \\
\hline Drinking alcohol ${ }^{9}$ & $80(70)$ & $79(83)$ & $159(77)$ & $65(51)$ & $66(64)$ & $128(57)$ \\
\hline Drinking no alcohol & $33(30)$ & $16(17)$ & $49(23)$ & $59(49)$ & $37(36)$ & $96(43)$ \\
\hline
\end{tabular}

${ }^{1}$ married/living with a partner.

${ }^{2}$ completion of nine-year compulsory school, senior high-school.

${ }^{3}$ completion of university education.

${ }^{4}$ able to cover an unexpected cost of 14000 Swedish crowns (approximately 1400 Euros) within one week.

5 a small village in the countryside with mainly single-family houses.

${ }^{6}$ a densely built-up area, in a quarter of a town or in a suburb.

${ }^{7}$ smokes regularly/sometimes.

${ }^{8}$ using snuff (a Swedish smokeless tobacco) regularly/sometimes.

${ }^{9}$ drinking 1-9 glasses/week.

horse ownership (Fisher's exact test $p=0.018$ ), participation in outdoor recreational PA because of the feeling of well-being (Fisher's exact test $p=0.003$ ), and participation in PA indoors (Pearson chi-square $=10.447, p=$ 0.001 ) were factors that significantly enhanced participation in outdoor recreational PA.

\section{Differences between groups and factors significantly associated with participation in outdoor recreational PA among men}

Factors that were associated significantly with outdoor recreational PA among all men, with and without children, were a higher level of education (Pearson chisquare $=8.220, p=0.004), \operatorname{dog}$ or horse ownership (Pearson chi-square $=11.527, p=0.001)$, participation in PA for physical reasons (Pearson chi-square $=19.859$, $p<0.001$ ), participation for the adventure (Pearson chisquare $=9.888, p=0.002$ ), access to appropriate areas to perform outdoor recreational PA (Fisher's exact test $p=0.026)$, interest (Pearson chi-square $=4.928, p=$ 0.026 ), and participation in PA indoors (Pearson chisquare $=20.439, p<0.001$ ).

Factors that significantly enhanced participation in outdoor recreational PA among men with children were dog or horse ownership (Pearson chi-square $=5.804$, $p=0.016)$, participation in PA for physical reasons
(Pearson chi-square $=10.880, p=0.001)$, participation for the adventure (Pearson chi-square $=10.108, p=$ 0.001 ), and participation in PA indoors (Pearson chisquare $=6.435 p=0.011$ ). Factors that significantly enhanced participation in outdoor recreational PA among men with no children were a higher education level (Pearson chi-square $=9.481, p=0.002$ ), living in a town (Pearson chi-square $=4.407, p=0.036$ ), $\mathrm{dog}$ or horse ownership (Fisher's exact test $p=0.009$ ), participation in PA for physical reasons (Pearson chi-square = 8.548, $p=0.003$ ), time availability (Pearson chi-square $=$ $4.214, p=0,040)$, interest (Pearson chi-square $=5.766$, $p=0.016$ ), and participation in PA indoors (Pearson chisquare $=15.699, p<0.001)$.

\section{Factors predicting the probability of participation in outdoor recreational PA among men and women}

Variables significantly associated with an increased probability of participating in outdoor recreational PA among all women and men, irrespective of whether or not they had children, are presented in Table 4. No factors were significantly associated with the probability of participating in outdoor recreational PA among women with or without children in the final models. Our data indicate that for women, irrespective of whether they had children or not, dog or horse ownership, the 
Table 2 All independent variables included in the first model

\begin{tabular}{|c|c|c|}
\hline \multirow[t]{2}{*}{ Variables } & \multicolumn{2}{|c|}{ Coded as } \\
\hline & 0 & 1 \\
\hline Cohabiting & $\overline{\text { yes }^{1}}$ & $\mathrm{no}^{2}$ \\
\hline Level of education & lower ${ }^{3}$ & higher $^{4}$ \\
\hline Personal financial situation & able $e^{5}$ & not able ${ }^{6}$ \\
\hline Living conditions & countryside ${ }^{7}$ & town ${ }^{8}$ \\
\hline Owning a dog or horse & yes & no \\
\hline Smoking habits & smoker $^{9}$ & non-smoker ${ }^{10}$ \\
\hline Snuff habits & snuffer ${ }^{11}$ & non-snuffer ${ }^{12}$ \\
\hline Alcohol habits & drinker $^{13}$ & non-drinker ${ }^{14}$ \\
\hline Able to participate in as much outdoor recreational PA as wanted & yes & no \\
\hline Participated in outdoor recreational PA for physical reasons & yes & no \\
\hline Participated in outdoor recreational PA for social reasons & yes & no \\
\hline Participated in outdoor recreational PA for the adventure & yes & no \\
\hline Participated in outdoor recreational PA for well-being & yes & no \\
\hline Not able to participate in as much outdoor recreational PA as wanted due to costs & yes & no \\
\hline Not able to participate in as much outdoor recreational PA as wanted due to physical level & yes & no \\
\hline Not able to participate in as much outdoor recreational PA as wanted due to family situation & yes & no \\
\hline Not able to participate in as much outdoor recreational PA as wanted due to illness/functional disorder & yes & no \\
\hline Not able to participate in as much outdoor recreational PA as wanted due to lack of appropriate areas & yes & no \\
\hline Not able to participate in as much outdoor recreational PA as wanted due to lack of knowledge & yes & no \\
\hline Not able to participate in as much outdoor recreational PA as wanted due to lack of equipment & yes & no \\
\hline Not able to participate in as much outdoor recreational PA as wanted due to lack of time & yes & no \\
\hline Not able to participate in as much outdoor recreational PA as wanted due to lack of courage & yes & no \\
\hline Not able to participate in as much outdoor recreational PA as wanted due to lack of interest & yes & no \\
\hline Participated in PA indoors & yes & no \\
\hline Abandoned outdoor recreational PA during the evening due to fear of violence & yes $^{15}$ & no ${ }^{16}$ \\
\hline
\end{tabular}

The logistic regression analysis evaluated factors with a significant influence on the participation in outdoor recreational physical activity (PA).

${ }^{1}$ married/living with a partner.

${ }^{2}$ single or living apart.

${ }^{3}$ completed nine-year compulsory school, senior high school.

${ }^{4}$ completed university education.

5 able to cover an unexpected cost of 14000 Swedish crowns (approximately 1400 Euros) within one week.

${ }^{6}$ not able to cover an unexpected cost of 14000 Swedish crowns within one week.

${ }^{7}$ living in a small village in the countryside with mainly single-family houses.

${ }^{8}$ living in a densely built-up area, in a quarter of a town, or in a suburb.

${ }^{9}$ smokes regularly/sometimes.

${ }^{10}$ stopped smoking/never smoked.

${ }^{11}$ using snuff (smokeless tobacco) regularly/sometimes.

${ }^{12}$ stopped using snuff/never used it.

${ }^{13}$ drinking 1-9 glasses/week.

${ }^{14}$ drinking no alcohol.

${ }^{15} \mathrm{often} /$ rather often.

${ }^{16}$ never/seldom.

interaction of dog or horse ownership and the ability to cover an unexpected cost, as well as participation in PA indoors, were factors significantly associated with an increased probability of participation in outdoor recreational PA.

For men, irrespective of child status, dog or horse ownership, the interaction of dog or horse ownership and participation in PA for physical reasons and a family situation that permitted outdoor recreational PA were factors significantly associated with an increased probability of participating in outdoor recreational PA. For men without children, the interaction between dog or horse ownership and participation in PA indoors, the interaction between dog or horse ownership and participation in PA for physical reasons, and higher levels of education were factors significantly associated with an increased probability of participation in outdoor recreational PA. For men with children, the interaction between dog or horse ownership and participating in PA for physical reasons, and participation in PA indoors 
Table 3 Outdoor recreational physical activities carried out during the last 12 months

\begin{tabular}{|c|c|c|c|c|c|c|}
\hline & $\begin{array}{l}\text { Men with } \\
\text { children }\end{array}$ & $\begin{array}{l}\text { Men without } \\
\text { children }\end{array}$ & All men & $\begin{array}{l}\text { Women with } \\
\text { children }\end{array}$ & $\begin{array}{l}\text { Women without } \\
\text { children }\end{array}$ & $\begin{array}{l}\text { All } \\
\text { women }\end{array}$ \\
\hline Factor & $\begin{array}{l}n=113 \\
(\%)\end{array}$ & $\begin{array}{l}n=95 \\
(\%)\end{array}$ & $\begin{array}{l}n=208 \\
(\%)\end{array}$ & $\begin{array}{l}n=121 \\
(\%)\end{array}$ & $\begin{array}{l}n=103 \\
(\%)\end{array}$ & $\begin{array}{l}n=224 \\
(\%)\end{array}$ \\
\hline Outdoor recreational $\mathrm{PA}^{* 1}$ & $71(63)$ & $64(67)$ & $135(65)$ & $87(72)$ & $84(82)$ & $171(76)$ \\
\hline Strolling/walking ${ }^{2}$ & $46(41)$ & $33(35)$ & $79(38)$ & $58(52)$ & $57(55)$ & $115(51)$ \\
\hline Exercising $^{3}$ & $42(37)$ & $46(48)$ & $88(42)$ & $53(44)$ & $51(50)$ & $104(46)$ \\
\hline Aquatic sports ${ }^{4}$ & $46(41)$ & $48(51)$ & $94(45)$ & $62(51)$ & $51(50)$ & $113(50)$ \\
\hline Winter sports $s^{5}$ & $17(15)$ & $11(12)$ & $28(14)$ & $21(17)$ & $6(6)$ & $27(12)$ \\
\hline Gardening & $79(70)$ & $37(39)$ & $116(56)$ & $70(58)$ & $39(38)$ & 109 (49) \\
\hline Indoor $\mathrm{PA}^{* 6}$ & $44(39)$ & $63(66)$ & $107(51)$ & $39(32)$ & $61(59)$ & $100(45)$ \\
\hline $\begin{array}{l}\text { Participation in non-strenous } \\
\text { activities }^{7}\end{array}$ & $55(49)$ & $60(63)$ & $115(55)$ & $78(65)$ & $58(56)$ & $136(61)$ \\
\hline
\end{tabular}

${ }^{1}$ participated in several times per month to every day during the last 12 months, all activities below included.

${ }^{2}$ strolling, walking, Nordic walking, golf.

${ }^{3}$ jogging, rollerblading, biking, orienteering, cross-country riding.

${ }^{4}$ canoeing, diving, bathing.

${ }^{5}$ cross country skiing, skating, downhill skiing, tobogganing.

${ }^{6}$ floorball, weight training, aerobics, swimming, gymnastics.

${ }^{7}$ hunting, sunbathing, angling, camping, bird watching, motorboating, sailing.

*Physical activity.

significantly increased the probability of participating in outdoor recreational PA.

\section{Discussion}

The main findings indicate that the majority of the women and men had participated in outdoor recreational PA several times a month to every day during the 12months prior to one month before pregnancy. More factors came into effect if men were physically active outdoors compared to women. However, for both women and men, having a dog or a horse seemed to be the most important factor associated with the probability of participation in outdoor recreational PA. Participation in PA indoors was also associated with participation in outdoor recreational PA for both women and men. Economic situation was significant when analysing all women

Table 4 Binary logistic regression predicting independent factors significantly associated with the probability of participating in outdoor recreational physical activity

\begin{tabular}{|c|c|c|c|c|c|c|c|c|c|c|c|c|}
\hline & $\begin{array}{l}\text { Men with } \\
\text { children }\end{array}$ & & & $\begin{array}{l}\text { Men without } \\
\text { children }\end{array}$ & & & $\begin{array}{l}\text { All } \\
\text { men }\end{array}$ & & & $\begin{array}{l}\text { All } \\
\text { women }\end{array}$ & & \\
\hline Factors & OR & $\begin{array}{l}\mathrm{Cl} \\
(95 \%)\end{array}$ & $\mathbf{p}$ & OR & $\begin{array}{l}\mathrm{Cl} \\
(95 \%)\end{array}$ & $\mathbf{p}$ & OR & $\begin{array}{l}\mathrm{Cl} \\
(95 \%)\end{array}$ & p & OR & $\begin{array}{l}\mathrm{Cl} \\
(95 \%)\end{array}$ & $\mathbf{p}$ \\
\hline Higher education level & n.s. & n.s. & n.s. & 4.211 & $\begin{array}{l}1.316- \\
13.473\end{array}$ & 0.015 & n.s. & n.s. & n.s. & n.s. & n.s. & n.s. \\
\hline Dog or horse ownership & n.s. & n.s. & n.s. & n.s. & n.s. & n.s. & 3.419 & $\begin{array}{l}1.167- \\
10.019\end{array}$ & 0.025 & 24.523 & $\begin{array}{l}3.220- \\
186.778\end{array}$ & 0.002 \\
\hline Permissive family situation* & n.s. & n.s. & n.s. & n.s. & n.s. & n.s. & 3.084 & $\begin{array}{l}1.206- \\
7.884\end{array}$ & 0.019 & n.s. & n.s. & n.s. \\
\hline $\begin{array}{l}\text { Dog or horse ownership and } \\
\text { physical reasonst }\end{array}$ & 5.214 & $\begin{array}{l}1.123- \\
6.897\end{array}$ & 0.001 & 13.583 & $\begin{array}{l}2.964- \\
62.240\end{array}$ & 0.001 & 5.570 & $\begin{array}{l}2.405- \\
12.904\end{array}$ & 0.001 & n.s. & n.s. & n.s. \\
\hline $\begin{array}{l}\text { Dog or horse ownership and } \\
\text { indoor activities } \neq\end{array}$ & n.s. & n.s. & n.s. & 13.585 & $\begin{array}{l}3.327- \\
55.476\end{array}$ & 0.001 & n.s. & n.s. & n.s. & n.s. & n.s. & n.s. \\
\hline $\begin{array}{l}\text { Dog or horse ownership and } \\
\text { economy\# }\end{array}$ & n.s. & n.s. & n.s. & n.s. & n.s. & n.s. & n.s. & n.s. & n.s. & 2.705 & $\begin{array}{l}1.021- \\
7.168\end{array}$ & 0.045 \\
\hline Indoor activities & 2.783 & $\begin{array}{l}1.430- \\
9.967\end{array}$ & 0.027 & n.s. & n.s. & n.s. & n.s. & n.s. & n.s. & 4.047 & $\begin{array}{l}1.929- \\
8.488\end{array}$ & 0.001 \\
\hline
\end{tabular}

*Having a family situation that allowed participation in outdoor recreational physical activity.

tInteraction variable measuring dog or horse ownership and participation in outdoor recreational physical activity for physical reasons.

₹ Interaction variable measuring dog or horse ownership and participation in physical activity indoors.

\# Interaction variable measuring dog or horse ownership and ability to cover an unexpected cost.

१Participation in physical activity indoors.

$\mathrm{OR}$, odds ratio; $\mathrm{Cl}$, confidence interval; n.s., not significant. 
together. For men, irrespective of whether they had children or not, the physical aspect, i.e. improved physical condition, staying power and vigour, played a significant role. For all men, a family situation that allowed PA was important to participation in outdoor recreational PA.

PA is a wide-ranging term that includes a variety of activities that may occur in many different settings and modes and at varying frequencies and intensities. This complexity makes it difficult to measure. However, our definition of PA included a broad range of activities. Participants were given examples of activities in the questionnaire and were allowed to evaluate the various activities that they participated in over the course of a year. The intensity and type of activity can vary widely during a year; the seasons are likely to influence both the level of activity and the chosen activity [22].

Participants reported only how often they had participated in outdoor recreational PA during the previous 12 months (up to one month before pregnancy) and not the intensity or time, which would have provided more information about their habits. Bias may exist due to the retrospective nature of the study. Data collection at the population level often involves self-reported measures through the use of questionnaires. This study strategy is frequently employed for reasons of practicality, low cost, and general acceptance [23]. Self-reports are useful for gaining insight into PA patterns in populations although there is always a risk of over- and underestimation of the answers. Indeed, the measurement method may have a significant impact on the observed levels of PA; self-reported measures of PA were both higher and lower than those measured directly [24]. Even selfreports about smoking and alcohol consumption may cause systematic errors and should be treated with caution $[25,26]$.

The participants in this study included the majority of pregnant women and their partners within the defined geographical area. However, since the rate of nonparticipation was fairly high (48\%), generalising the findings must be done with caution. Non-response can affect the validity of epidemiological studies and introduce bias [27]. Response quality is also important in the sense that incomplete or incorrectly-answered questionnaires will have the same effects as a poor response. The questionnaires were completed very well by the participants in this study. Accordingly, the internal validity was very low, which must be regarded as a strength of the study. The participants probably remembered whether or not they participated in outdoor recreational PA during the last 12 months although the number of times might be misleading. Other strengths are that we included both women and men and that the distribution according to gender was almost equal, as well as the distribution of both women and men with and without children. The classification of the different outdoor recreational physical activities carried out during the last 12 months was at first made by all the authors separately and then compared. There was no disagreement among the authors about the classification.

In contrast to previous studies $[1,11,12]$, which stated that women tend to be less physically active than men, $76 \%$ of the women and $65 \%$ of the men included in our study participated in outdoor recreational PA during the 12-month period prior to one month before pregnancy. This observation may be explained by our inclusion of a wider spectrum of outdoor activities, not only activities strongly associated with sports and exercise that are traditionally pursued mostly by men. Women, both with and without children, were found to stroll and walk significantly more than men. These findings are in agreement with previous work [28] demonstrating that women of all ages tend to walk more than men.

Dog or horse ownership emerged as a factor that was strongly associated with participation in outdoor recreational PA among both men and women in this study. We chose to focus on dogs and horses, since these animals require exercise and involve outdoor recreational PA for the owner. Our findings corroborate other studies [29], demonstrating that dog owners spend more time in mild to moderate PA compared to non-dog owners. We also found that men who had a dog or a horse and participated in outdoor recreational PA for physical reasons were more capable of being active. This finding might indicate that men who have an interest in PA for physical reasons tend to have a dog or a horse. Since having pets, especially a horse, involves additional expense, people in a better financial situation are more likely to have a dog or a horse. Along the same lines, we noted that women who were able to cover an unexpected cost and had a dog or a horse participated more in outdoor recreational PA than women who did not. However, some of the groups that this data refer to have less than five participants and caution may be needed when drawing conclusions.

Participation in PA indoors was associated with participation in outdoor recreational PA, both for women and men. A trend towards polarisation can be seen, in which the population is divided into those who perform PA and those who do not [30]. Accordingly, it seems that people active in PA are active independent of indoor or outdoor activities. Both women and men without children participated in PA indoors significantly more than those who had children. This occurrence may be explained by the fact that healthcare PA is easier to perform outdoors with children than indoors. This finding underscores the importance of midwives informing parents-to-be of the positive health effects of outdoor recreational PA, especially since the majority of 
women and men reported that outdoor recreational activities had a positive impact on their well-being. Other studies [4-6] have also shown a positive relationship between green space and self-perceived health. PA that is not physically strenuous e.g. sunbathing, bird watching and hunting (we have defined hunting based on Swedish conditions, where hunting mostly means sitting and waiting for the animal to show up), were among the most widely pursued activities among both women and men. These types of activity may have a restorative effect on people's health and should not be underrated [8].

In Sweden, as in many other countries, there are differences in participation in PA among different groups in society. Lower levels of PA are more common among individuals with lower education levels than among those with a higher level of education [31,32]. In this study, men without children and with a higher level of education were more likely to perform outdoor recreational PA than those with a lower level of education.

Men, irrespective of whether they had children or not, who had a family situation that permitted outdoor recreational PA, participated in activities to a greater extent than men without such a family situation. As previous work has mainly focused on the PA of women, to our knowledge no similar findings have been reported. Previously, women listed lack of time, social support, family commitments and role obligations as barriers to their participation in PA [18-21], factors which are included in the family situation. Our findings thus indicate a need for more research focusing on PA of men who become parents.

Contradictory reports exist regarding the impact of age and number of children on participation in PA [33-37]. We focused only on the differences between women and men with and without children; accordingly, we have not studied how age and number of children may affect participation in outdoor recreational PA.

Becoming a parent is a life-changing event that affects participation in PA, probably due to lifestyle changes. Pregnancy and parenthood have been found to be life events associated with decreased PA $[14,15]$. The decline is seen mostly among women, possibly explained by a research focus on women's perception of and influences on their children's PA patterns. Bellows-Riecken and Rhodes [15] reviewed 31 studies published from 1989 through to July 2007 that dealt with the impact of parenthood on PA. Of the 25 independent samples, 17 focused on women, seven included both women and men, and only one was based solely on men. This review, in addition to the results from this study, demonstrate the need for a greater focus on men's PA during this life transition, as both parents play an important role in shaping their children's routines (including PA habits). There would generally appear to be a stronger influence of fathers' PA patterns on both boys and girls [38].

\section{Conclusions}

The majority of the women and men had participated in outdoor recreational PA from several times per month up to every day during the 12 -month period prior to one month before pregnancy. More factors affected whether men were physically active than women. Dog or horse ownership seemed to be an important factor associated with the probability of participating in outdoor recreational PA. Those active in PA are also active independent of indoor or outdoor activities. Our findings also indicate that becoming a parent is a lifechanging event that affects participation in PA. Midwives and health promoters have an important role to play, encouraging both parents to be active and to support each other by offering family-oriented PA choices that involve parents and children or that provide an opportunity for parents to perform PA while their children are involved in their own activities. Further studies dealing with gender differences are needed in this field. The promotion of outdoor recreational PA, which also has restorative effects on well-being, needs to focus on activities that are attractive and affordable for the majority of both men and women.

\section{Acknowledgements}

We are grateful to the participants in this study. We are also grateful to Maria Sjögren and all the midwives at Trossö and Lyckeby antenatal clinics for their help with data collection. We also thank Claes Jogréus for statistical advice. This study was supported with grants from the Blekinge Research Council.

\section{Author details}

${ }^{1}$ Faculty of Medicine, Department of Clinical Sciences in Malmö, General Practice, Lund University, CRC entrance 72:28:11, Malmö University Hospital, 20502 Malmö, Sweden. ${ }^{2}$ School of Health Science, Blekinge Institute of Technology, 37179 Karlskrona, Sweden.

\section{Authors' contributions}

KS and LS were responsible for the conception, design and acquisition of data. KS was responsible for the analysis and interpretation of data and drafting the initial manuscript. LS and EEH were responsible for reviewing all drafts of the manuscript. All authors read and approved the final manuscript.

\section{Competing interests}

The authors declare that they have no competing interests.

Received: 26 April 2010 Accepted: 10 February 2011

Published: 10 February 2011

\section{References}

1. US Department of Health and Human Services: The Surgeon General's report on physical activity and health. Washington DC: US Government Printing Office; 1996.

2. Warburton DER, Nicol CW, Bredin SSD: Health benefits of physical activity: the evidence. Canadian Medical Association Journal 2006, 174:801-809.

3. Physical Activity Guidelines Advisory Committee: Physical Activity Guidelines Advisory Committee Report, 2008. Washington DC: Department of Health and Human Services; 2008. 
4. Maas J, Verheij RA, Groenewegen PP, de Vries S, Spreeuwenberg P: Green space, urbanity, and health: how strong is the relation? Journal of Epidemiology and Community Health 2006, 60:587-592.

5. Maas J, Verheij RA, de Vries P, Spreeuwenber P, Schellevis FG, Groenewegen PP: Morbidity is related to a green living environment. Journal of Epidemiology and Community Health 2009, 63:967-973.

6. Mitchell R, Popham F: Greenspace, urbanity and health: relationships in England. Journal of Epidemiology and Community Health 2007, 61:681-683.

7. Frumkin $\mathrm{H}$ : Beyond toxicity human health and the natural environment American Journal of preventive Medicine 2001, 20:234-240.

8. Kaplan R, Kaplan S: The experience of nature: A psychological perspective. Cambridge University Press; 1989.

9. Fredman P, Karlsson SE, Romlid U, Sandell K: Vad är friluftsliv? Delresultat från en nationell enkät om friluftsliv och naturturism i Sverige. [What is outdoor life? Partial results from a national survey about outdoor life and nature tourism in Sweden]. [http://urn.kb.se/resolve?urn=urn:nbn:se: miun:diva-7783], Retrieved January 24, 2011.

10. World Health Organization: Global health risks: mortality and burden of disease attributable to selected major risks. Geneva, Switzerland: World Health Organization; 2009 [http://www.who.int/healthinfo/ global_burden_disease/GlobalHealthRisks_report_full.pdf], Retrieved February 5, 2011, from.

11. Sjöström M, Oja P, Hagströmer B, Smith J, Bauman A: Health-enhancing physical activity across European Union countries: the Eurobarometer study. Journal of Public Health 2006, 5:291-300.

12. Leslie E, Fotheringham MJ, Owen N, Bauman A: Age-related differences in physical activity levels of young adults. Medicine \& Science in Sports \& Exercise 2001, 33:255-258.

13. King AC, Kiernan M, Ahn D, Wilcox S: The effects of marital transition on changes in physical activity: results from a 10-year community study. Annals of Behavioral Medicine 1998, 20:64-69.

14. Allender S, Hutchinson L, Foster C: Life-change events and participation in physical activity: a systematic review. Health Promotion International 2008, 23:160-172.

15. Bellows-Riecken $\mathrm{KH}$, Rhodes RE: A birth of inactivity? A review of physical activity and parenthood. Preventive Medicine 2008, 46:99-110.

16. Brown WJ, Mishra G, Lee C, Bauman A: Leisure time physical activity in Australian women: relationship with well-being and symptoms. Research Quarterly for Exercise and Sport 2000, 71:206-216.

17. Scmitz MKH, Jacobs DR, Schreiner PJ, French S, Lewis CE, Caspersen CJ, Sidney S, Sternfeld B: The impact of becoming a parent on physical activity: The CARDIA Study. AHA conference proceedings. 39th Annual Conference on Cardiovacular Disease Epidemiology and Prevention. American Heart Association. Circulation 1999, 99:1104-1108.

18. Fahrenwald NL, Walker SN: Application of the transtheoretical model of behavior of change to the physical activity behavior of WIC mothers. Public Health Nursing 2003, 20:307-317.

19. Fahrenwald NL, Shangreaux P: Physical activity behaviour of American Indian mothers. Orthopaedic Nursing 2006, 25:22-29.

20. Miller YD, Trost SG, Brown WJ: Mediators of physical activity behavior change among women with young children. American Journal of Preventive Medicine 2002, 23:98-103.

21. Verhoef MJ, Love EJ: Women and exercise participation: The mixed blessings of motherhood. Health Care for Women International 1994, 4:297-306

22. Matthews CE, Freedson PS, Herbert JR, Stanek EJ III, Merriam PA, Rosal MC, Ebbeling CB, Ockene IS: Seasonal variation in household, occupational and leisure time physical activity: Longitudinal analyses from the seasonal variation of Blood Cholesterol Study. American Journal of Epidemiology; 2001:2:172-183.

23. Dishman RK, Washburn RA, Schoeller DA: Measurement of physical activity. QUEST 2001, 53:295-309.

24. Prince SA, Adamo KB, Hamel ME, Hardt J, Connor Gorber S, Trembley M: A comparison of direct versus self-reported measures for assessing physical activity in adults: a systematic review. International Journal of Behavioral Nutrition and Physical Activity 2008, 5:56.

25. Connor Gorber S, Schofield-Hurwitz S, Hardt J, Levasseur G, Tremblay M, The accuracy of self-reported smoking: A systematic review of the relationship between self-reported and cotinine-assessed smoking status. Nicotine \& Tobacco Research 2009, 11:12-24
26. Midanik LT: The validity of self-reported alcohol consumption: A literature review. British Journal of Addiction 1988, 77:357-382

27. Edwards P, Roberts I, Clarke M, DiGuiseppi C, Pratap S, Wentz R, Kwan I: Increasing response rates to postal questionnaires: systematic review. British Medical Journal 2002, 324:1183-1192.

28. Simpson ME, Serdula M, Galuska DA, Gillespie C, Donehoo R, Macera C, Mack K: Walking trends among US adults. The behavioral risk factor surveillance system 1987-2000. American Journal of Preventive Medicine. 2003, 25:95-100

29. Brown SG, Rhodes RE: Relationships among dog ownership and leisure time walking in western Canadian adults. American Journal of Preventive Medicine 2006, 30:131-136.

30. Södergren M, Sundquist J, Johansson SE, Sundquist K: Physical activity, exercise and self-rated health: a population based study from Sweden. BMC Public Health. 2008, 8:352.

31. Borodulin K, Laatikainen T, Lahti-Koski M, Jousilahti P, Lakka TA: Association of age and education with different types of leisure-time physical activity among 4437 Finnish adults. Journal of Physical Activity and Health 2008, 5:242-251.

32. Lindström M, Hanson BS, Östergren P-O: Socioeconomic differences in leisure-time physical activity: the role of social participation and social capital in shaping health related behaviour. Social Science and Medicine 2001, 52:441-451.

33. Nomaguchi KM, Bianchi SM: Exercise time, gender differences in the effects of marriage, parenthood, and employment. Journal of Marriage and the Family 2004, 66:413-430.

34. Brown WJ, Trost SG: Life transitions and changing physical activity patterns in young women. American Journal of Preventive Medicine 2003, 25:140-143.

35. Sternfeld B, Ainsworth BE, Queensbury CP: Physical activity patterns in a diverse population of women. Preventive Medicine 1999, 28:313-323.

36. Fahrenwald NL, Atwood JR, Johnson DR: Mediator analysis of Moms on the move. Western Journal of Nursing Research 2005, 27:271-291.

37. Sallis JF, Greenlee L, McKenzie TL, Broyles SL, Zive MM, Berry CC, Brennan J, Nader PR: Changes and tracking of physical activity across seven years in Mexican-American and European-American mothers. Women Health 2001, 29:1-13.

38. Shropshire J, Carroll B: Family variables and children's physical activity: Influence of parental exercise and socio-economic status. Sport Education and Society 1997, 2:95-116.

\section{Pre-publication history}

The pre-publication history for this paper can be accessed here: http://www.biomedcentral.com/1471-2458/11/93/prepub

\section{doi:10.1186/1471-2458-11-93}

Cite this article as: Sjögren et al:: Parenthood and factors that influence outdoor recreational physical activity from a gender perspective. BMC Public Health 2011 11:93.

\section{Submit your next manuscript to BioMed Central and take full advantage of:}

- Convenient online submission

- Thorough peer review

- No space constraints or color figure charges

- Immediate publication on acceptance

- Inclusion in PubMed, CAS, Scopus and Google Scholar

- Research which is freely available for redistribution

Submit your manuscript at www.biomedcentral.com/submit
C Biomed Central 